\title{
INFLUENCE OF OXYGEN ADSORPTION ON ELECTRONIC STRUCTURE OF IRON PHTHALOCYANINE
}

\author{
B. Bialek and P. Brąiglel \\ Institute of Physics, Pedagogical University \\ Al. Armii Krajowej 13/15, 42-200 Częstochowa, Poland
}

\begin{abstract}
Self-consistent field $a b$ initio calculations were performed in order to determine the electronic structure of iron phthalocyanine ( $\mathrm{FePc}$ ) and its changes under interaction with the $\mathrm{O}_{2}$ molecule. The experimental evidence related to $\mathrm{O}_{2}$ adsorption on phthalocyanine plane was confirmed. The possible charge transfer between phthalocyanine and $\mathrm{O}_{2}$ molecule is briefly discussed. Considerable displacement of energy levels in the case of oxygen adsorption on FePc plane has been noticed.
\end{abstract}

PACS numbers: $71.10 .+\mathrm{x}$

\section{Introduction}

Phthalocyanines (Pcs) are materials well known and widely applied in the nowadays industry. Various Pcs compounds are mostly used in the electronics, e.g. as semiconducting devices [1-3], solar cells $[4,5]$, rectifying devices [6] and, more recently, liquid crystals [7], gas sensors [8] and low-dimensional conducting materials [9].

The applications mentioned above are due to the fact that the conductivity value $(\sigma)$ of the metal substituted phthalocyanines (MPcs), which is usually in the semiconducting range $\left(\sigma<10^{-10} \mathrm{~S} / \mathrm{cm}\right)[2]$ in certain conditions can considerably increase up to even $1000 \mathrm{~S} / \mathrm{cm}$. For example the presence of doping agents is conducive to such increase in conductivity [10].

The electrical properties of MPcs are determined mainly by the electronic valence band structure of these materials. Therefore, it is very important to find out exactly what the electronic structure of these compelling complexes is and how it changes under the influence of surrounding atmosphere. The answers to these questions are essential when application of phthalocyanine compounds as gas sensors is concerned.

A lot of theoretical and experimental works have already been done in order to precisely specify the electronic properties of considered complexes [11]. Confiding on the literature studies one can find that important investigations of the electronic structure of the MPcs were done as early as in the 1970s. At that time ultraviolet photoelectron spectroscopy (UPS) spectra of some metal substituted 
phthalocyanines were reported [12-15]. Then surface photovoltage spectroscopy (SPS) spectra of MPcs ( $\mathrm{M}=\mathrm{Ni}, \mathrm{Fe}, \mathrm{Co}, \mathrm{Cu}, \mathrm{Zn}$ ) were presented by Dahlberg and Musser $[16,17]$. They have not only investigated the electronic structure of MPcs but also its changes under the influence of oxygen adsorption.

Although the experimental works yield very useful information about the electronic structure of solids, it is, however, not always possible to give an explanation of the results obtained. Therefore, there were also many theoretical studies the aim of which was to understand the experimentally observed shape of the photoemission spectra through examining the electronic properties of single phthalocyanine molecule. Such treatment is possible because in the condensed phase the Pcs molecules retain their individual characteristic to a large degree. This concerns the structure of phthalocyanine in the crystalline form: the distance between molecules is over $3 \AA$; thus, correlative interactions between them are mainly of van der Waals type and the electronic structure of single molecule is only slightly influenced by the presence of its neighbours.

To our knowledge the electronic structure of transition metal substituted phthalocyanines has been calculated only by using extended Hückel (EH) model [18]. Most advanced methods, for example CNDO, MNDO or VEH (valence effective Hamiltonian) were used in the case only of metal free $\mathrm{Pc}\left(\mathrm{H}_{2} \mathrm{Pc}\right)[19-21]$ and $\mathrm{CuPc}$ [22].

As, among others, the iron phthalocyanine $(\mathrm{FePc})$ is an important technological material, we think that revision of its electronic properties on higher, both experimental and theoretical, level is still significant. In this paper the results of $a b$ initio calculations of the electronic structure of FePc are presented. In order to check whether the theoretical treatment can be useful for explaining changes of the electrical properties under the influence of oxidant agents, comparison of the configuration obtained for $\mathrm{FePc}$ with the electronic structure of $\mathrm{FePc}-\mathrm{O}_{2}$ complex is carried out.

\section{Computational details}

Calculations were performed with GAUSSIAN 92 program package [23]. The geometry of the considered $\mathrm{FePc}$ molecule used in our calculation is shown in Fig. 1. $D_{4 h}$ symmetry was assumed. Both angles and bond lengths are the same as for the $\mathrm{CuPc}$ in our previous work [24]. The distance $1.93 \AA$ between the central metal ion and an inner nitrogen atom was taken [25].

Calculations were done with the use of the standard STO-3G basis set both for the case of isolated $\mathrm{FePc}$ molecule and for $\mathrm{FePc}-\mathrm{O}_{2}$ complex. $\mathrm{O}_{2}$ molecule was taken to be located above the metal atom - such location is experimentally supported. A perpendicular orientation towards the FePc plane was considered (Fig. 2). The $\mathrm{O}_{2}$ orientation was chosen arbitrarily as in both perpendicular and parallel positions towards the Pc plane effective bond formation is possible. The perpendicular one had this advantage that fourfold symmetry axis was preserved. The total energy of complex was calculated for different distances between $\mathrm{O}_{2}$ molecule and $\mathrm{Fe}$ atom in order to find the equilibrium position. The distance varied from $1.5 \AA$ to $3.5 \AA$. 


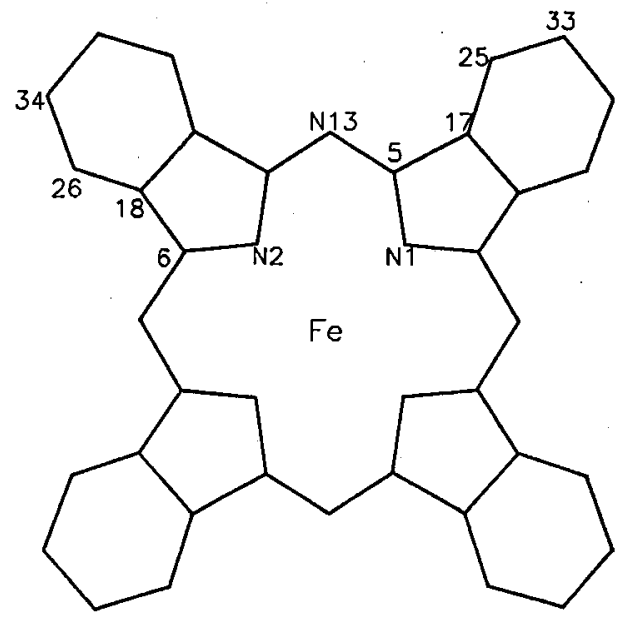

Fig. 1. The schematic view and the numbering system of FePc used in the present work.

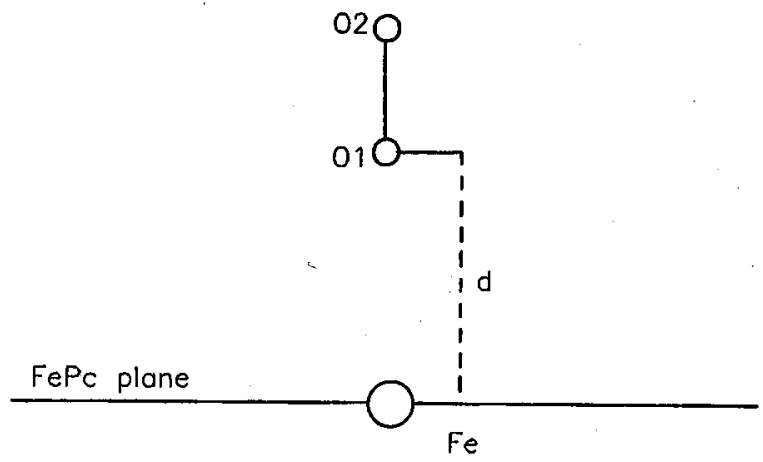

Fig. 2. Geometry of the considered $\mathrm{FePc}-\mathrm{O}_{2}$ system; $d$ was varied from $1.5 \AA$ to $3.5 \AA$.

\section{Results and discussion}

Figure 3 illustrates changes of total energy of the $\mathrm{FePc}-\mathrm{O}_{2}$ system for different distances between $\mathrm{O}_{2}$ molecule and $\mathrm{FePc}$ plane. This graph confirms the experimental evidence that $\mathrm{O}_{2}$ adsorbs above the central metal in the $\mathrm{Pc}$ ring in undissociated form [26]. When distance between $\mathrm{O}_{2}$ and FePc is $2.1 \AA$ energy of the complex is minimal and the system is most stable. Therefore our analysis of the electronic structure of the $\mathrm{FePc}-\mathrm{O}_{2}$ complex is performed just for this case.

In Table I the results of the Mulliken population analysis for iron phthalocyanine when is both isolated and interacting with $\mathrm{O}_{2}$ molecule are presented. The results of our $a b$ initio calculations are compared with those obtained for FePc by Schaffer et al. with EH method. As is seen from the data, the $a b$ initio results are in good accordance with the EH ones as far as population on phthalocyanine ligand is concerned. As for metal population, although the total charge on Fe ion is almost 


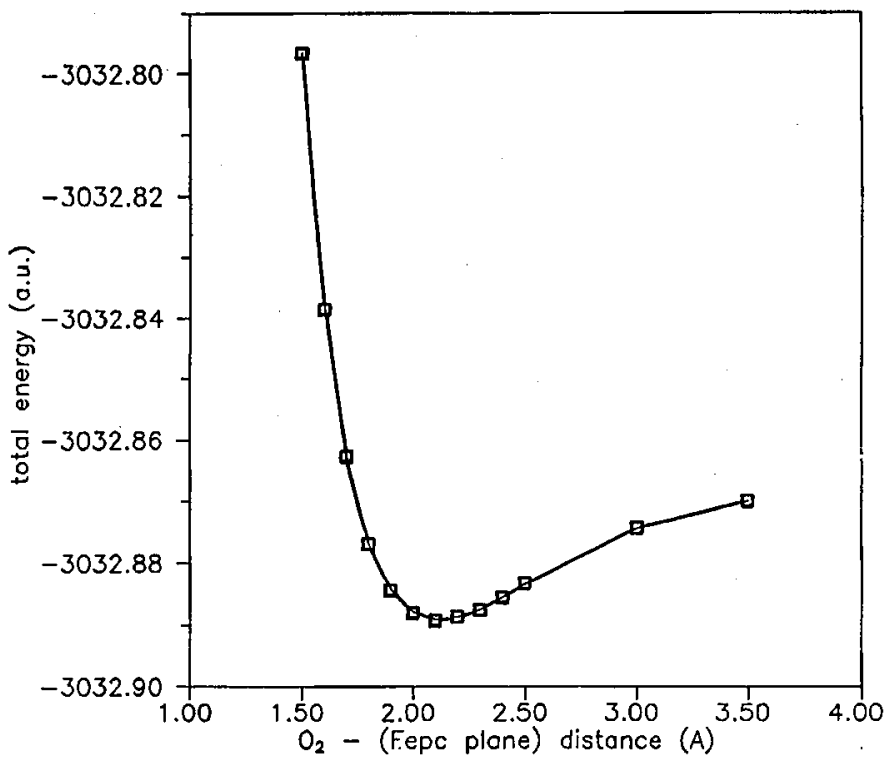

Fig. 3. Dependence of the total energy of $\mathrm{FePc}-\mathrm{O}_{2}$ system on distance $d$ between $\mathrm{FePc}$ plane and $\mathrm{O}_{2}$ molecule.

TABLE I

Electronic population of $\mathrm{FePc}$ and $\mathrm{FePc}-\mathrm{O}_{2}$ complex.

\begin{tabular}{c|c|c|c}
\hline \hline \multirow{2}{*}{ Atom $^{*}$} & \multicolumn{2}{|c|}{$\mathrm{FePc}$} & \multirow{2}{*}{$\begin{array}{c}\text { FePc-O } \\
\text { ab }\end{array}$} \\
\cline { 2 - 3 } & EH method [18] & ab initio & ab itio \\
\hline $\mathrm{N} 1$ & 5.120 & 5.302 & 5.417 \\
$\mathrm{~N} 13$ & 5.198 & 5.200 & 5.187 \\
$\mathrm{C} 6$ & 3.924 & 3.793 & 3.783 \\
$\mathrm{C} 18$ & 3.995 & 3.992 & 4.000 \\
$\mathrm{C} 26$ & 4.031 & 4.041 & 4.033 \\
$\mathrm{C} 34$ & 4.039 & 4.049 & 4.056 \\
\hline $\mathrm{Fe}(3 d)$ & 7.136 & 6.753 & 5.430 \\
$\mathrm{Fe}(4 s)$ & 0.301 & 0.221 & 0.418 \\
$\mathrm{Fe}(4 p)$ & 0.314 & 0.734 & 1.237 \\
\hline $\mathrm{O} 1(2 p)$ & & & 4.371 \\
$\mathrm{O} 2(2 p)$ & & & 4.220 \\
\hline $\mathrm{Net} \mathrm{Fe}$ & 0.249 & 0.292 & 0.915 \\
\hline
\end{tabular}

*Numbering of atoms according to Figs. 1 and 2. 
the same in both cases (EH 7.751, ab initio 7.708), there is a certain difference in the charge distribution on the specific valence $\mathrm{Fe}$ orbitals. The configuration on $\mathrm{Fe}$ atom figured up in $\mathrm{EH}$ calculations is $(3 d)^{7.136}(4 s)^{0.301}(4 p)^{0.314}$ while our treatment leads to the $(3 d)^{6.753}(4 s)^{0.221}(4 p)^{0.734}$ arrangement. The largest difference is observed in an occupation of $3 d$ and $4 p$ orbitals. This fact is not surprising however, as in our previous $a b$ initio calculations of the electronic structure of copper phthalocyanine $(\mathrm{CuPc})$ we noticed similar charge shift within the metal ion orbitals when compared with the results obtained with the use of the less advanced quantum-chemical methods [24]. Additionally, analysis of density matrix indicates that transfer of electrons is still the same as in the other MPcs' case: from the ring $\pi$ orbitals to $4 p_{z}$ orbital of $\mathrm{Fe}$ and from $3 d$ orbitals of $\mathrm{Fe}$ to the molecular orbitals of the $e_{g}$ symmetry.

When $\mathrm{FePc}$ is interacting with $\mathrm{O}_{2}$ the net metal charge is increased to 0.915 . The net oxygen molecule charge is negative and equal to -0.591 . The charges on all atoms of $\mathrm{Pc}$ ligand are hardly different from the respective ones of $\mathrm{FePc}$ not influenced by oxygen. Reduction of the electron population of the $3 d$ orbitals and simultaneous increase in the population of $4 p$ orbitals on $\mathrm{Fe}$ indicate that charge transfer from the metal to the adsorbed $\mathrm{O}_{2}$ results in a charge transfer from the $\mathrm{Pc}$ orbital to the metal. Thus, the effective bond in the $\mathrm{FePc}-\mathrm{O}_{2}$ system is formed both with $\mathrm{Fe}$ ion $d$ orbitals and with the ring $e_{g}$ orbital.

TABLE II

Energy of occupied levels of $\mathrm{FePc}$ and $\mathrm{FePc}-\mathrm{O}_{2}$ system (in eV).

\begin{tabular}{c|c|c||c|c|c}
\hline \hline $\begin{array}{c}\mathrm{FePc} \\
\text { gas phase* }^{*}\end{array}$ & $\begin{array}{c}\mathrm{FePc} \\
(\text { ab initio })\end{array}$ & $\begin{array}{c}\mathrm{FePc}-\mathrm{O}_{2} \\
(\text { ab } \text { initio }) \\
-\varepsilon\end{array}$ & $\begin{array}{c}\mathrm{FePc} \\
\text { gas phase* } \\
{[15]}\end{array}$ & $\begin{array}{c}\mathrm{FePc} \\
(a b \text { initio }) \\
-\varepsilon\end{array}$ & $\begin{array}{c}\mathrm{FePc}-\mathrm{O}_{2} \\
(a b \text { initio }) \\
-\varepsilon\end{array}$ \\
\hline & 3.72 & 2.29 & $9.00 \mathrm{sh}$ & 9.53 & 9.78 \\
$6.36 \mathrm{~s}$ & 3.75 & 4.13 & & 9.64 & 10.07 \\
& 4.73 & 4.36 & $9.25 \mathrm{pw}$ & 9.88 & 10.25 \\
& 5.98 & 6.38 & & 9.91 & 10.37 \\
& 7.33 & 7.49 & & 9.96 & 10.54 \\
$6.87 \mathrm{sh}, \mathrm{b}$ & 7.68 & 7.86 & $10.13 \mathrm{pw}$ & 10.39 & 11.03 \\
& 7.74 & 7.94 & & 10.69 & 11.03 \\
& 7.76 & 8.04 & $10.69 \mathrm{pw}$ & 10.95 & 11.09 \\
$8.38 \mathrm{sh}$ & 7.92 & 8.06 & & 10.96 & 11.38 \\
& 8.03 & 8.48 & & 11.30 & 12.11 \\
8.74 & 8.17 & 8.78 & $11.34 \mathrm{~b}$ & 11.88 & 12.47 \\
& 8.38 & 9.47 & $12.25 \mathrm{w}$ & 12.09 & 12.65 \\
& 9.29 & 9.52 & & & \\
\hline
\end{tabular}

*Notation: $\mathrm{s}=$ sharp, $\mathrm{b}=$ broad peak, $\mathrm{wp}=$ weak peak, $\mathrm{pw}=$ possible weak peak. 
Table II contains the calculated molecular orbitals (MO) energies for the $\mathrm{FePc}$ as well as for the $\mathrm{FePc}-\mathrm{O}_{2}$ complex. The self-consistent occupied orbital energies for $\mathrm{FePc}$ are compared with photoelectron spectrum of iron phthalocyanine vapours [15]. Since $a b$ initio method gives the discrete energy levels and, on the contrary, photoemission spectrum demonstrates rather broad bands, the comparison is not very fortunate. However, we can associate groups of discrete levels which are placed close one to another with the observed broad peaks. Then, taking also into account the fact that the same procedure as in this work was successfully applied to determination of the electronic structure of $\mathrm{CuPc}$ [24], we consider our $a b$ initio results obtained for $\mathrm{FePc}$ and $\mathrm{FePc}-\mathrm{O}_{2}$ complex to be reliable.

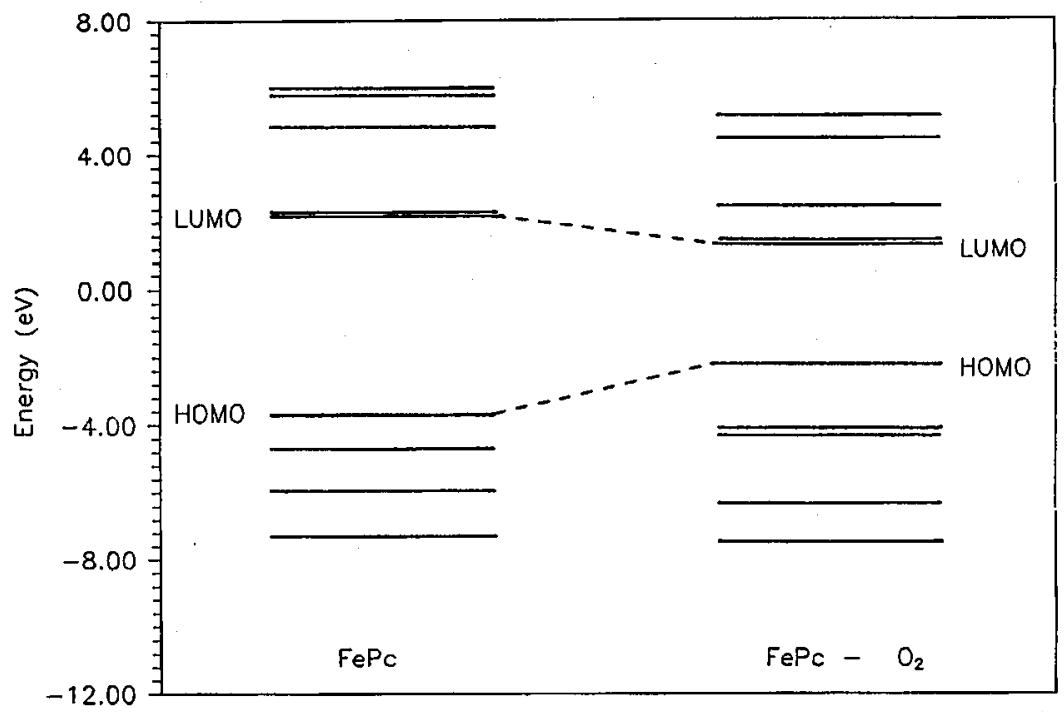

Fig. 4. HOMO-LUMO levels for $\mathrm{FePc}$ and $\mathrm{FePc}-\mathrm{O}_{2}$.

One can easily see that in the case of the $\mathrm{FePc}-\mathrm{O}_{2}$ interaction molecular orbitals are shifted in energy scale. For better illustration we present a diagram of a few lowest unoccupied and highest occupied energy levels (Fig. 4). As is seen the oxygen adsorption causes that the HOMO orbital is shifted up by $1.43 \mathrm{eV}$ and at the same time the LUMO orbital lowers by $0.75 \mathrm{eV}$. The resulting HOMO-LUMO gap is only $3.66 \mathrm{eV}$ wide, i.e. as much as $2.18 \mathrm{eV}$ narrower than in the $\mathrm{FePc}$ case. Considerable lowering of the unoccupied molecular orbitals - for three lowest MOs from energy levels (in eV) $2.12,2.22,4.79$ to $1.37,1.42,2.42$ respectively - and their drawing near one to another can cause the increasing conductivity of oxygen doping FePc, since group of these orbitals can form a new conducting band.

\section{Conclusions}

A $b$ initio calculations which we have carried out confirm the fact that when $\mathrm{FePc}$ is interacting with molecular oxygen placed above the central metal ion, the 
$\mathrm{O}_{2}$ adsorbs as the undissociated molecule and the stable $\mathrm{FePc}^{\delta+}-\mathrm{O}_{2}^{\delta-}$ complex is created. Such effect was predicted for other metal substituted phthalocyanines [17]. The electronic structure of the $\mathrm{FePc}-\mathrm{O}_{2}$ complex is changed considerably in comparison with the isolated FePc. Noticeable displacement of the energy levels resulting in the narrowing of the HOMO-LUMO gap leads to the formation of a new conduction band. This can explain the increasing conductivity of oxygen doped FePc.

\section{References}

[1] A.B.P. Lever, M.R. Hempstead, C.C. Leznoff, W. Lin, M. Melnik, W.A. Nevin, P. Seymour, Pure Appl. Chem. 58, 1467 (1986).

[2] H. Meier, Organic Semiconductors, Verlag Chimie, Weinheim 1974.

[3] M. Pope, C.E. Swenberg, Electronic Processes in Organic Crystals, Clarendon Press, Oxford 1982.

[4] J. Simon, J.J. André, Molecular Semiconductors, Springer, Berlin 1985, Ch. III.

[5] C.W. Tang, Appl. Phys. Lett. 48, 183 (1986).

[6] K. Abe, H. Sato, T. Kimura, Y. Ohkatsu, T. Kusano, Macromol. Chem. 190, 2693 (1989).

[7] J. Simon, C. Sirlin, Pure Appl. Chem. 61, 1625 (1989); 1, 148 (1990).

[8] Y. Sadaoka, T.A. Jones, W. Göpel, Sens. Acluat. B 1, 148 (1990).

[9] B. Hoffman, J.A. Ibers, Acc. Chem. Res. 16, 15 (1983).

[10] A. Gleizer, T.J. Marks, J.A. Ibers, J. Am. Chem. Soc. 97, 3545 (1975).

[11] T.J. Marks, Science 227, 881 (1985).

[12] W. Pong, J.A. Smith, J. Appl. Phys. 44, 174 (1973).

[13] H. Höst, A. Goldmann, S. Hüfner, H. Malter, Phys. Status Solidi B 76, 559 (1977).

[14] F.L. Battye, A. Goldmann, L. Kasper, Phys. Status Solidi B 80, 425 (1977).

[15] J. Berkowitz, J. Chem. Phys. 70, 2819 (1979).

[16] S.C. Dahlberg, M.E. Musser, J. Chem. Phys. 70, 5021 (1979).

[17] S.C. Dahlberg, M.E. Musser, J. Chem. Phys. 72, 6706 (1980).

[18] A.M. Schaffer, M. Gouterman, E.R. Davidson, Theor. Chim. Acta 30, 9 (1973).

[19] L.K. Lee, N.H. Sabelli, P.R. LeBreton, J. Phys. Chem. 86, 3926 (1982).

[20] E. Orti, J.L. Brédas, J. Chem. Phys. 89, 1009 (1988).

[21] P. Braqgiel, B. Szczepaniak, Mol. Cryst. Liq. Cryst. 229, 247 (1993).

[22] A. Henriksson, M. Sandbom, Theor. Chim. Acta 27, 303 (1972).

[23] M.J. Frish, G.W. Trucks, M. Head-Gordon, P.M.W. Gill, M.W. Wong, J.B. Foresman, B.G. Johnson, H.B. Schlegel, M.A. Robb, E.S. Replogle, R. Gomperts, J.L. Anders, K. Raghavachari, J.S. Binkley, C. Gonzalez, R.L. Martin, D.J. Fox, D.J. DeFrees, J. Baker, J.J.P. Stewart, J.A. Pople, in: Gaussian 92, Gaussian Inc. Pittsburgh PA, 1992.

[24] B. Szczepaniak, P. Bragiel, Vacuum 46, 465 (1995).

[25] J.F. Kirner, W. Dow, W.R. Scheidt, Inorg. Chem. 15, 1685 (1976).

[26] H. Alt, H. Binder, G. Sandstele, J. Catal. 28, 8 (1973). 